\title{
A Survey Study of Audiology Services during the Coronavirus Disease 2019 Pandemic in South Korea
}

\author{
InOn $\mathrm{Kim}^{1}$, Soo Hee $\mathrm{Oh}^{1,2}$ \\ ${ }^{1}$ Department of Audiology and Speech Language Pathology, Hallym Univesity of Graduate Studies, Seoul, Korea \\ ${ }^{2}$ Center for Hearing and Speech Research, Hallym University of Graduate Studies, Seoul, Korea
}

\author{
Received: July 26, 2021 \\ Revised: September 23, 2021 \\ Accepted: September 24, 2021 \\ Correspondence: \\ Soo Hee Oh, PhD \\ Department of Audiology and \\ Speech Language Pathology, Hallym \\ University of Graduate Studies, 427 \\ Yeoksam-ro, Gangnam-gu, Seoul \\ 06197, Korea \\ Tel: $+82-70-8680-6901$ \\ Fax: +82-2-3453-6618 \\ E-mail: osh503@naver.com
}

\begin{abstract}
Purpose: The coronavirus disease 2019 (COVID-19) pandemic has severely affected public health and people's lifestyle. The purpose of this survey study is to investigate audiology services during COVID-19 pandemic to understand the current audiology service situations in Korea and to improve audiology services. Methods: A total of 120 participants ( 60 audiologists and 60 clients visiting audiologists) were surveyed in this study using online or face-to-face methods. The participants answered 24 25 questions including current status of audiology service, communication difficulties with wearing masks, and the provision of tele-audiology services during COVID-19. Results: The results showed that both audiologists and clients with hearing loss still preferred face-to-face audiology services in COVID-19 situation in spite of $56 \%$ of visiting schedule delay and cancellation. The primary audiology services they considered in COVID-19 were hearing aid fitting and maintenance \& repair services. Wearing masks has led communication difficulties in both audiologists and clients with hearing loss due to speech level reduction, frequency filtering of sounds, and insufficient visual cues during the conversation. Only $30 \%$ of audiologists have provided tele-audiology services, and $4.4 \%$ of clients received tele-audiology services during COVID-19. Conclusion: The impacts of COVID-19 in audiology services in South Korea are still progressing. The technical and administrative systems and educational support to improve audiology services in South Korea are necessary.
\end{abstract}

Key Words: Audiology service, COVID-19, Pandemic, Audiology rehabilitation, Tele-audiology.

\section{INTRODUCTION}

전 세계적인 코로나바이러스감염증-19(코로나19; coronavirus disease 2019 [COVID-19])의 확산에 따라 세계 보건기구는 감염병 최고 경고 등급인 팬데믹(pandemic)을 선 언하였다(2020년 3월). 코로나19 치명률은 0.00 1.54\% (중윗 값 0.23\%)로 보고되었고(Ioannidis, 2021), 2021년 6월 4일 기 준 국내 감염자 수는 142,852 명, 사망자 수는 1,969 명으로 나타 났다(Ministry of Health and Welfare, 2021). 감염병 확산 방 지를 위해 국내에서는 사회적 거리두기 정책, 마스크 착용 의무 화, 외출 자제, 집합 금지, 운영 시간제한 등 강력한 코로나19 대 응책을 마련하여 시행하고 있다. 이러한 사회적 상황은 비대면 방식의 사회시스템 변화를 촉진하였으며, 청각재활서비스 영역

(c) This is an Open Access article distributed under the terms of the Creative Commons Attribution Non-Commercial License (https://creativecommons.org/ licenses/by-nc/4.0) which permits unrestricted non-commercial use, distribution, and reproduction in any medium, provided the original work is properly cited.
에서도 원격 청각재활 시스템의 구축과 활용에 대한 방안을 좀 더 모색하는 계기가 되었다.

$\operatorname{Gaeta}(2020)$ 는 미국에 거주하는 노인 150명을 대상으로 코 로나19 상황의 청각재활서비스와 마스크 착용으로 인한 의사소 통의 어려움에 대한 설문을 시행하였다. 응답자의 $29 \%$ 는 코로나 19 이후 대면 방문이 감소하였으며, $71 \%$ 는 코로나 19 이전과 동 일하게 또는 좀 더 자주 청각전문가를 방문한다고 응답하였다. 또한 전체 응답자의 $53 \%$ 가 마스크 착용으로 인해 의사소통 시 어려움을 느낀다고 하였으며, 이 중 $84 \%$ 는 마스크 착용으로 인 해 다소 또는 매우 어려움이 있다고 보고하였다. 보청기 착용 응 답자의 38\%는 마스크 착용 시 보청기 착용에 어려움이 있으며, 이외에도 마스크를 벗을 때 보청기의 분실이 우려된다고 답하여 마스크와 보청기를 동시에 착용하였을 때의 어려움을 알 수 있 었다. 한편 마스크를 착용한 상태에서 대화가 어려운 이유에 대 한 질문에서 응답자의 $48 \%$ 는 소리가 명료하지 않고 입 모양 등 시각적 단서를 활용할 수 없어서라고 답하였는데, 이는 난청인이 
마스크를 착용한 경우 소리가 명료하게 들리지 않고 시각적 단서 의 활용이 제한되기 때문에 의사소통에 더 큰 어려움을 초래할 수 있음을 보여준다.

사회적 거리두기는 난청인이 청력 저하 등 청각적 어려움이 있 음에도 불구하고 청력검사를 받거나 청각재활서비스를 이용하 는 데 불편함을 초래할 수 있다. 한 예로 Goldin et al.(2020)에 의하면 사회적 거리두기로 인해 2020년 2분기 보청기 판매량이 전년도에 비해 $58.6 \%, 3$ 분기 보청기 판매량은 $6.2 \%$ 감소하였고, 난청인은 코로나19 종식 이후에 보청기 구입을 위한 센터 방문 을 계획하는 것으로 나타났다. Alqudah et al.(2021)의 연구에 의하면 코로나 19 기간의 보청기 사용시간이 감소하였으며 이는 코로나19 봉쇄로 인해 보청기 전지의 소모와 보청기 적합, 관리 및 수리 서비스의 제약과 관련이 있는 것으로 설명하였다.

또한 마스크의 착용은 소리 감쇄, 말소리 명료도의 저하 및 입 모양 등 시각적 단서 활용의 제약을 초래하여 원활한 의 사소통에 어려움을 가져올 수 있다. 마스크를 착용한 상태 에서 대화 시 저역 통과 필터 효과가 발생해 말소리의 고주파 수(2,000 7,000 Hz) 대역 소리 감쇄가 일어난다(American Academy of Audiology, 2020; Goldin et al., 2020). 의료용 마스크(medical mask)는 3 4 dB SPL, N95 안면 마스크 (face mask)는 $2 \mathrm{kHz}$ 이상 주파수에서 12 14 dB SPL의 감쇄 를 보고하였다(Goldin et al., 2020). 또 다른 보고(American Academy of Audiology, 2020)에서도 마스크를 착용하지 않 은 상태와 비교하였을 때, 수술용 마스크(surgical mask)는 $5 \mathrm{~dB}$ SPL, KN95 마스크는 $8.7 \mathrm{~dB}$ SPL, N95 마스크는 $10.9 \mathrm{~dB}$ $\mathrm{SPL}$ 의 감쇄를 보였다. 투명창이 있는 마스크의 경우 그 종류에 따라 12 21 dB SPL의 소리 감쇄를 일으키고 마스크 위에 가림 막을 이중으로 착용한 경우 총 20 29 dB SPL의 감쇄를 초래 하였다. 최근 여러 연구에서 마스크 착용이 마스크 착용 화자의 말소리에 미치는 영향을 알아보고 마스크를 착용하였을 때 말 소리의 음향학적 변화를 보고하였다(Atcherson et al., 2021; Corey et al., 2020; Nguyen et al., 2021).

코로나19는 기존 대면 방식의 청각재활서비스 이용에 어려움 을 가져왔고 대면 청각재활서비스 제공 방법의 변화를 추구하는 계기가 되었다. 원격 청각재활서비스는 기존 대면 청각재활서비 스의 대안적 서비스 제공 방법으로 향후 활용 가능성이 높다. 상 담, 청력검사, 보청기와 인공와우 적합, 청능재활 등 다양한 서비 스가 원격으로 가능하나(Kim et al., 2021) 국내외적으로 원격 청각서비스 시스템의 구축과 그 활용은 아직까지 미비한 실정이 다. Saunders and Roughley(2021)의 연구에 의하면 청각전문 가들이 원격 청각재활의 필요성은 인지하고 있으나, 원격 서비스 지원의 한계점, 장비 부족, 검사의 어려움, 원격 서비스의 질에 대 한 부정적 인식 등의 이유로 청각전문가의 원격 서비스 제공에
어려움이 있다고 보고하였다. 또 다른 설문 연구(Gaeta, 2020) 에서는 노인도 화상회의 시스템인 스카이프(Skype), 페이스타임 (FaceTime)을 활용하고 있으며 향후 원격 청각재활서비스의 확 대가 필요하다고 응답하였으나, 대면서비스에 비해 원격 청각재 활서비스의 유용성은 사람들이 낮게 평가하고 있는 것으로 나타 났다.

아직까지 코로나19 기간 동안 국내 청각재활서비스의 이용 현 황에 대한 연구는 보고된 바가 없다. 팬데믹 상황에서 국내 청각 재활서비스 현황을 파악하는 것은 비대면 상황에서 난청인의 청 각재활서비스 이용의 어려움을 이해하고 서비스 향상을 위한 기 반 마련을 위해 필요하다. 본 연구에서는 코로나 19 상황에서 청 각재활서비스를 제공하는 청각전문가와 청각서비스를 이용하는 난청인을 대상으로 설문을 시행하였다. 이를 통해 코로나19 상 황에서 국내 청각재활서비스의 제공 및 이용 현황을 파악하고 팬데믹 상황에서 겪을 수 있는 청각전문가와 난청인의 어려움을 이해하고자 하였다. 연구 결과는 향후 청각재활서비스의 변화 방 향을 모색하고 청각재활서비스 향상을 위한 기반 마련에 도움이 될 것으로 생각된다.

\section{MATERIALS AND METHODS}

\section{연구 대상}

본 연구는 2021년 4월부터 5월까지의 기간 동안 청각재활서 비스를 제공하는 청각전문가 60 명과 청각재활서비스 이용을 위 해 센터를 방문한 고객 60 명, 총 120 명을 대상으로 설문을 시행 하였다(Table 1). 응답 고객 중 현재 청각기기를 사용하는 사람 은 45 명, 청각기기를 사용하지 않는 사람은 15 명이었다. 청각전 문가의 70\%는 보청기 센터에서 근무하고 있었으며 40\%가 6년 이상의 실무 경험이 있었다. 고객의 $60 \%$ 는 보청기를 착용하고 있었다.

\section{설문지 구성}

Gaeta(2020)의 설문 연구를 참고하여 총 25문항의 청각전 문가 설문과 24 문항의 난청 고객용 설문지를 작성하였다. 설문 응답자가 느낀 불편함을 자유롭게 기술하는 마지막 1 개의 주관 식 문항을 제외하고는 모두 객관식이었고 문항에 따라 한 개 또 는 그 이상의 답변 선택이 가능하도록 하였다. 설문의 내용은 마 스크 착용으로 인한 불편함, 사회적 거리두기로 인한 대면 청각 재활서비스 제공 방식의 변화, 원격 청각재활서비스에 대한 의견 을 포함하였다. 설문문항 작성(Demetriou et al., 2015)에서 먼 저 설문의 주제는 코로나19 상황에서 청각전문가와 고객이 생각 하는 국내 청각재활서비스 현황 파악으로 설정하고, 설문 항목 은 대상자의 배경 정보, 청력 정도, 코로나19가 미치는 영향, 원 
Table 1. Demographic information of respondents

\begin{tabular}{|c|c|c|}
\hline Category & Professional (\%) & Client (\%) \\
\hline \multicolumn{3}{|l|}{ Age (yr) } \\
\hline $20 \sim 29$ & 26.6 & 7.0 \\
\hline $30 \sim 39$ & 35.0 & 14.0 \\
\hline $40 \sim 49$ & 15.0 & 1.7 \\
\hline $50 \sim 59$ & 23.3 & 24.5 \\
\hline $60 \sim 69$ & & 21.0 \\
\hline $70 \sim 79$ & & 21.0 \\
\hline$\geq 80$ & & 0.5 \\
\hline \multicolumn{3}{|l|}{ Sex } \\
\hline Male & 50.0 & 65.0 \\
\hline Female & 50.0 & 35.0 \\
\hline \multicolumn{3}{|l|}{ Work place } \\
\hline Hearing aid center & 70.0 & NA \\
\hline Hearing device manufacturer & 10.0 & NA \\
\hline Hospital & 10.0 & NA \\
\hline Educational institute & 16.6 & NA \\
\hline Unemployment & 1.6 & NA \\
\hline \multicolumn{3}{|l|}{ Years of work experiences (yr) } \\
\hline$<1$ & 6.6 & NA \\
\hline $1 \sim 5$ & 53.3 & NA \\
\hline $6 \sim 10$ & 20.0 & NA \\
\hline$\geq 10$ & 20.0 & NA \\
\hline \multicolumn{3}{|l|}{ Types of hearing devices } \\
\hline Hearing aid & NA & 60.0 \\
\hline Cochlear implant & NA & 8.3 \\
\hline Bimodal & NA & 6.6 \\
\hline No hearing device & NA & 25.0 \\
\hline
\end{tabular}

NA: not applicable

격 청각재활서비스에 대한 구체적 내용을 포함하였다. 질문은 일 상에서 주로 사용하는 이해하기 쉬운 표현과 명확한 단어를 사 용하여 답변자가 질문의 의미를 쉽게 이해하고 응답할 수 있도록 하였다. 답변 형식은 질문에 따라 이분법, 객관식 보기, 리커트 척도(likert scale)를 혼용하였다. 객관식 질문에서 보기의 내용 과 개수는 질문에 따라 차이를 두었다. 예를 들어 "귀하가 현재 보청기를 사용하고 있다면 사용하는 보청기 형태는 무엇입니까" 라는 질문의 보기는 '귀걸이형(BTE, RIC 등 포함)' '귓속형(ITC, CIC 등 포함)', '기타', '청각기기 사용 안함'의 총 4개 보기를 제 시한 뒤 선택하도록 하였다. 또한 리커트 척도의 경우 "마스크의 착용으로 인한 보청기(청각 기기) 착용 후 활동 시 어려움은 어느 정도입니까?”라는 질문에 '어려움 없음, '경도 어려움, '중도 어 려움, '고도 어려움, '완전 어려움'의 5 개 보기를 제시하였다.

\section{설문 방법}

설문은 구글폼(Google Form)을 활용한 온라인 설문과 직접 대면 설문 방식으로 시행하였다. 구글폼 설문의 경우 대상자에 게 구글폼 온라인 링크를 통해 설문에 답하도록 하였고, 직접 대 면 설문은 설문지를 인쇄하여 청각재활서비스 센터를 방문한 고 객이 작성하도록 하였다. 설문 작성시간은 약 15 20분 내외로 소요되었다. 본 연구는 한림국제대학원대학교 생명윤리심의위원 회의 승인(HUGSAUD509467)을 받아 시행하였다.

\section{데이터 분석}

전문가와 고객의 설문 응답을 각각 요약 분석하였다. 항목별 로 코로나19 상황에서 마스크 착용으로 인한 불편함, 사회적 거 리두기로 인한 직접 대면 방문의 변화, 원격 청각재활서비스 활 용 현황 등을 정리하였다. SPSS version 12.0 (IBM Corp., Armonk, NY, USA)을 사용하여 통계검사를 시행하였고 Spearman correlation과 Kruskal Wallis 비모수 검정을 시 행하여 유의수준 0.05 를 기준으로 분석하였다.

\section{RESULTS}

\section{청각전문가 설문 결과}

Table 2는 설문에 참여한 60명 청각전문가의 응답을 요약한 표이다. 응답자의 약 $56 \%$ 가 코로나 19 이후 고객의 예약이 미뤄 지거나 취소됐으며 방문 예약이 감소했다고 하였다. 약 $98 \%$ 의 청각전문가는 마스크를 착용한 상태에서 고객과의 대화가 경도 이상의 어려움이 있다고 답하였고 전체 응답의 $20 \%$ 는 마스크를 착용한 상태에서 대화 시 고심도 이상의 어려움을 겪는다고 하 였다. 마스크 착용 후 대화가 어려운 이유로는 고객이 전문가가 말하는 소리를 잘 이해하지 못하기 때문이 $64 \%$ 로 가장 많았고 소리 크기가 작아졌기 때문은 $19 \%$ 였다. 마스크 착용으로 대화 가 어려운 경우 청각전문가의 $60 \%$ 는 소리를 크고 분명하게 다시 말하는 것으로 보고하였다. 약 $42 \%$ 이상의 전문가는 마스크 착 용을 고려하여 보청기를 선정하고 적합한다고 응답하였다.

$65 \%$ 의 청각전문가는 코로나 19 상황에서 대면 방문을 통한 직 접 서비스의 제공을 선호하였으며, $13 \%$ 는 원격 청각서비스를 선 호하였다. 전문가가 판단했을 때 코로나19 상황에서 고객이 선호 하는 청각서비스 방식은 직접 대면 방식이 $33 \%$ 로 가장 많았고, $25 \%$ 의 원격서비스, $24 \%$ 의 가정방문서비스 순으로 응답하였다. 현재 코로나19 상황에서의 청각서비스 제공 방식은 방문 대면 방 식이 $67 \%$ 로 가장 많았고 다음으로 우편, 택배 방식이 $17 \%$ 였다. 고객에게 직접 대면서비스를 제공하지 못하는 경우 서비스 제공 에서 가장 힘들다고 생각하는 영역은 보청기 적합이 $36 \%$ 로 가 장 많았고 관리와 수리는 $26 \%$, 청력평가 $15 \%$, 청능훈련 $12 \%$, 
Table 2. A summary of questionnaire for professionals providing hearing care services

\begin{tabular}{|c|c|}
\hline Question & $\begin{array}{l}\text { Single or multiple } \\
\text { choice responses (\%) }\end{array}$ \\
\hline \multicolumn{2}{|c|}{ What changes are there in the face-to-face visits of hearing loss clients due to COVID-19? } \\
\hline Visit on the scheduled date & 43.7 \\
\hline Delay the schedule & 39.4 \\
\hline Cancel a reservation or visit & 16.9 \\
\hline \multicolumn{2}{|c|}{ Is there a change in the number of face-to-face visitors due to COVID-19? } \\
\hline Increase & 1.7 \\
\hline Stay the same & 41.7 \\
\hline Decrease & 56.7 \\
\hline \multicolumn{2}{|c|}{ How difficult is the conversation with the clients due to wearing a mask in COVID-19 situation? } \\
\hline No difficulty & 1.7 \\
\hline Mild difficulty & 33.3 \\
\hline Moderate difficulty & 45.0 \\
\hline Severe difficulty & 13.3 \\
\hline Profound difficulty & 6.7 \\
\hline \multicolumn{2}{|c|}{ Why is it difficult to communicate with clients when wearing a mask? } \\
\hline Clients can`t understand professional’s speaking & 63.6 \\
\hline Professional can `t understand client’s speaking & 10.2 \\
\hline Soft speech sounds & 19.3 \\
\hline Others & 6.8 \\
\hline \multicolumn{2}{|c|}{ What do you do when you have difficulty communicating with clients with masks? } \\
\hline Ask to remove his/her mask & 0.0 \\
\hline Remove my mask & 21.7 \\
\hline Speak one more time loudly & 59.8 \\
\hline Write down the message & 18.5 \\
\hline \multicolumn{2}{|c|}{$\begin{array}{l}\text { When talking to a customer wearing a mask, have you ever used a smartphone's voice recognizer app to convert the } \\
\text { sound of speech into text messages? }\end{array}$} \\
\hline Yes & 11.7 \\
\hline No & 88.3 \\
\hline \multicolumn{2}{|c|}{ Have you ever selected and adjusted hearing aids considering the impact of wearing masks? } \\
\hline Hearing aid type & 44.6 \\
\hline Hearing aid fitting & 42.2 \\
\hline Not considerate & 13.3 \\
\hline \multicolumn{2}{|c|}{ What do you prefer when providing hearing rehabilitation services to your clients in COVID-19 situations? } \\
\hline In-person visit & 64.5 \\
\hline Remote hearing service & 13.2 \\
\hline Video telephone service & 3.9 \\
\hline Telephone service & 5.3 \\
\hline Home visit service & 6.6 \\
\hline No preference & 6.6 \\
\hline \multicolumn{2}{|c|}{ What do you think is the client's preferred method of hearing rehabilitation services in COVID-19 situations? } \\
\hline In-person visit & 33.3 \\
\hline Remote hearing service & 25.0 \\
\hline Video telephone service & 3.6 \\
\hline Telephone service & 4.8 \\
\hline Home visit service & 23.8 \\
\hline No preference & 9.5 \\
\hline \multicolumn{2}{|c|}{ What is the current method of providing auditory rehabilitation compared to before COVID-19? } \\
\hline Ask to visit center anytime (stay the same) & 43.8 \\
\hline Ask to visit centers only for necessary & 23.6 \\
\hline Provide remote hearing service & 9.0 \\
\hline Provide home visit service & 2.2 \\
\hline Provide telephone service & 4.5 \\
\hline Provide parcel delivery service & 16.9 \\
\hline
\end{tabular}


Table 2. Continued

\begin{tabular}{|c|c|}
\hline Question & $\begin{array}{l}\text { Single or multiple } \\
\text { choice responses (\%) }\end{array}$ \\
\hline \multicolumn{2}{|c|}{$\begin{array}{l}\text { What did you feel most uncomfortable about when the client couldn't visit the hearing aid center or hearing professionals } \\
\text { in COVID-19 situation? }\end{array}$} \\
\hline Hearing evaluation & 15.4 \\
\hline Hearing aid fitting & 35.8 \\
\hline Maintenance \& repair & 26.0 \\
\hline Auditory training & 12.2 \\
\hline Counselling & 10.6 \\
\hline \multicolumn{2}{|c|}{ Have clients visited hearing aid centers or hearing professionals during social distance periods? } \\
\hline Yes & 96.7 \\
\hline No & 3.3 \\
\hline \multicolumn{2}{|c|}{ If you provided face-to-face services to clients during social distance periods, what services did you provide? } \\
\hline Hearing evaluation & 23.4 \\
\hline Hearing aid fitting & 28.0 \\
\hline Maintenance \& repair & 24.6 \\
\hline Auditory training & 9.1 \\
\hline Counselling & 14.9 \\
\hline \multicolumn{2}{|c|}{ Have you ever provided services using remote systems to clients during social distance periods? } \\
\hline Yes & 31.7 \\
\hline No & 68.3 \\
\hline \multicolumn{2}{|c|}{ If you provided remote hearing rehabilitation services to the clients, what services did you provide? } \\
\hline Hearing evaluation & 7.1 \\
\hline Hearing aid fitting & 64.3 \\
\hline Maintenance \& repair & 7.1 \\
\hline Auditory training & 7.1 \\
\hline Counselling & 14.3 \\
\hline \multicolumn{2}{|c|}{ Compared to face-to-face services, what do you think about the quality of remote hearing rehabilitation services? } \\
\hline Estimated as very low quality & 30.0 \\
\hline Estimated as low quality & 60.0 \\
\hline Estimated as the same quality & 10.0 \\
\hline \multicolumn{2}{|c|}{ What service would you like to provide remotely as a hearing professional in situations like COVID-19? } \\
\hline Hearing evaluation & 6.9 \\
\hline Hearing aid fitting & 47.1 \\
\hline Maintenance \& repair & 10.3 \\
\hline Auditory training & 19.5 \\
\hline Counselling & 14.9 \\
\hline Others & 1.1 \\
\hline \multicolumn{2}{|l|}{ What are the advantages of providing remote services to clients? } \\
\hline Place \& time free & 40.7 \\
\hline Immediate service provision & 29.2 \\
\hline Less waiting time & 19.5 \\
\hline Easy reflection of everyday real situation & 9.7 \\
\hline Others (lack of skills to use remote system) & 0.9 \\
\hline \multicolumn{2}{|l|}{ What are the disadvantages of providing remote services to clients? } \\
\hline Less reliable relationship with clients & 14.3 \\
\hline Difficulties of hearing aid fine tuning & 23.3 \\
\hline Lack of skills or systems to use remote system & 39.1 \\
\hline Lack of close conversation with clients & 2.3 \\
\hline Lack of clients using built-in remote system in hearing aids & 18.8 \\
\hline Others & 2.2 \\
\hline
\end{tabular}

COVID-19: coronavirus disease 2019 
상담 $11 \%$ 의 응답을 보였다. $97 \%$ 청각전문가가 코로나 19 상황에 서도 고객이 센터를 방문했다고 답하였고, 사회적 거리두기 기간 에도 대면 보청기 적합, 관리 및 수리, 청력검사, 상담, 청능훈련 의 서비스를 일부(9 28\%) 제공하였다고 보고하여 코로나19 상 황에서도 대부분 직접 대면서비스를 제공하고 이를 선호함을 알 수 있었다.

청각전문가의 $68 \%$ 는 원격 청각재활서비스를 제공한 경험이 없었으며 원격서비스를 제공한다면 $64 \%$ 가 보청기 적합을 제공 하겠다고 하였다. $31.7 \%$ 의 청각전문가만이 보청기 조절과 상담 영역에서 원격 청각재활서비스를 제공한 경험이 있다고 응답하 였다. 또한 $90 \%$ 는 대면서비스에 비해 원격서비스의 질이 떨어 질 것 같다고 응답하였고, 원격서비스의 질에 대한 청각전문가의 신뢰도가 매우 낮음을 확인할 수 있었다. 코로나 19 상황에서 제 공하고 싶은 원격 청각서비스는 보청기 적합이 $47 \%$ 로 가장 많 았고 청능훈련 $19 \%$, 상담 $15 \%$ 를 보였다. 원격 청각의 장점은 시 간과 장소에 구애받지 않는다는 점이 $41 \%$ 로 가장 많았고, $29 \%$ 는 즉각적 서비스 제공이 가능한 점, $20 \%$ 는 대기시간의 감소를 들었다. 원격 청각서비스의 단점은 고객이 원격 시스템을 활용 하는 기술이나 원격 시스템의 부족이 $39 \%$ 로 가장 많았고, 보청 기 미세조절의 어려움이 $23 \%$, 원격 시스템이 내장된 고가의 보 청기 사용자가 적음 $(19 \%)$, 고객과의 신뢰성 있는 관계 형성 부족 (14\%)을 들었다.

\section{난청 고객 설문 결과}

청각재활서비스를 받기 위해 전문가를 방문한 총 60 명 고객이 설문에 참여하였다. 응답자 중 청각보조기기를 사용하는 사람 은 45명(보청기 36명, 인공와우 5명, 바이모달 4명)이었고, 사용 하지 않은 사람은 15 명이었다. Table 3 은 청각기기를 사용하는 45명 고객의 설문 응답을 요약한 표이다.

본인의 청력 정도에 대한 질문에서 고객 응답자의 $80 \%$ 가 청력 이 나쁘다고 대답하였고 78\%는 코로나19 상황에서 청력이 예전 보다 더 중요하게 생각된다고 답변하였다. 청각전문가와 마찬가 지로 약 $98 \%$ 의 고객은 마스크를 착용한 상태에서 고객과 대화 시 경도 이상의 어려움이 있다고 답하였고 전체 응답의 $36 \%$ 는 마스크를 착용한 상태에서 고심도 이상의 어려움을 겪는다고 하 였다. 마스크 착용 후 대화가 어려운 이유로는 소리 크기가 작아 졌기 때문이 $53 \%$ 로 가장 많았고 입 모양을 읽지 못해서가 $36 \%$, 얼굴 표정을 읽지 못해서가 $11 \%$ 순으로 나타났다. 흥미롭게도 마스크 착용으로 대화가 어려운 경우 아무것도 하지 않는다는 고객이 50\%로 가장 많았고 크고 분명하게 다시 말하도록 요청 하는 경우는 $35 \%$ 였다.

마스크와 청각기기를 동시에 착용할 경우 $80 \%$ 이상이 착용 시 경도 이상의 어려움이 있다고 하였고 전체의 $22 \%$ 는 착용 시
고심도의 어려움이 있다고 하였다. 또한 마스크와 청각기기를 동 시에 착용하고 활동할 경우 $76 \%$ 가 경도 이상의 어려움을 보고 하여 마스크와 청각기기를 동시에 착용한 경우 착용과 활동에서 어려움을 겪고 있음을 알 수 있었다.

93\%의 고객은 코로나 19 상황에서 필요 시 대면서비스를 위해 센터를 직접 방문할 것이라고 응답하였다. $78 \%$ 의 고객은 코로나 19 상황에서 대면 방문을 통한 직접 서비스의 제공을 선호하였 으며, 그 다음으로 $16 \%$ 는 전화 서비스를 선호하는 것으로 나타 나, 앞서 기술한 전문가가 생각하는 코로나19 상황에서 고객이 선호하는 청각서비스 방식과는 좀 차이가 있는 것으로 나타났 다. 전문가는 고객이 직접 대면 방식(33\%), 원격서비스( $25 \%)$, 가 정방문(24\%)의 순으로 선호서비스를 생각하였지만, 고객은 대 면 방식을 훨씬 더 많이(78\%) 선호하였고 다음으로 전화서비스 (16\%)를 선호하는 것으로 나타났다. 현재 코로나19 상황에서의 청각서비스를 제공받는 방법으로, 방문 대면 방식이 $90 \%$ 로 가 장 많았고 다음은 전화서비스로 $8 \%$ 였다. 고객이 직접 대면서비 스를 받지 못하는 경우 가장 불편하게 생각하는 서비스 영역은 보청기 적합이 $53 \%$ 로 가장 많았고 관리와 수리는 $43 \%$ 로 나타 나 주로 보청기 적합과 관리 측면에서 어려움이 있음을 알 수 있 었다. $93 \%$ 고객은 사회적 거리두기 기간에도 보청기 센터를 방 문했다고 답하였고, 제공받은 대면서비스는 보청기 적합(50\%) 과 관리 및 수리( $40 \%)$, 청력검사(9\%)의 순으로 나타나 사회적 거 리두기 상황에서도 대부분 직접 대면서비스를 제공받았고 이를 선호함을 알 수 있었다.

고객의 96\%는 원격 청각재활서비스를 받은 경험이 없다고 보 고하였으며 응답의 $2 \%$ 만이 상담 영역의 원격 청각서비스를 받 았다고 보고하였다. 또한 78\%는 대면서비스에 비해 원격서비스 의 질이 떨어질 것 같다고 응답하여 청각전문가와 마찬가지로 원 격서비스의 질에 대한 전반적 신뢰도가 낮음을 확인할 수 있었 다. 코로나19 상황에서 제공하고 싶은 원격 청각서비스는 보청기 적합이 $47 \%$ 로 가장 많았고 관리와 수리가 $29 \%$ 를 보여 고객이 청각기기의 적합, 관리 및 수리 관련 서비스가 필요하고 이를 중 요하게 생각하고 있음을 알 수 있었다. 또한 $82 \%$ 가 줌(Zoom)과 같은 화상회의 시스템을 사용한 경험이 없는 것으로 나타나 원 격 시스템 사용 경험이 적은 것으로 나타났다.

\section{마스크 착용으로 인한 난청인의 어려움}

Table 4는 청각전문가와 청각재활서비스를 받는 고객(청각기 기 착용자 45 명, 청각기기 미착용자 15 명)의 마스크 착용으로 인한 의사소통의 어려움을 비교한 표이다. 표에 나타난 3개 그 룹 응답자 중 청각전문가와 청각기기를 착용한 고객 각각 $65 \%$ 와 $75 \%$ 가 중도 이상의 어려움이 있다고 보고하였다. 반면 청각기기 를 착용하지 않은 응답자의 $27 \%$ 는 중도 이상의 어려움이 있다고 
Table 3. A summary of questionnaire for clients receiving hearing care services

\begin{tabular}{|c|c|}
\hline Question & $\begin{array}{l}\text { Single or multiple } \\
\text { choice responses (\%) }\end{array}$ \\
\hline \multicolumn{2}{|l|}{ How good do you think your hearing is? } \\
\hline Very good & 2.2 \\
\hline Good & 4.4 \\
\hline Normal & 13.3 \\
\hline Bad & 51.1 \\
\hline Very bad & 28.8 \\
\hline \multicolumn{2}{|c|}{ How has the importance of your hearing changed in the COVID-19 situation? } \\
\hline Much more important & 35.6 \\
\hline More important & 42.2 \\
\hline The same & 20.0 \\
\hline Less important & 2.2 \\
\hline Much less important & 0.0 \\
\hline \multicolumn{2}{|c|}{ How difficult is it to wear a mask in COVID-19 situation? } \\
\hline No difficulty & 2.2 \\
\hline Mild difficulty & 22.2 \\
\hline Moderate difficulty & 40.0 \\
\hline Severe difficulty & 22.2 \\
\hline Profound difficulty & 13.3 \\
\hline \multicolumn{2}{|c|}{ Why is it difficult to communicate with the other person when wearing a mask? } \\
\hline Can’t read lips & 35.8 \\
\hline Can’t read facial expression & 11.3 \\
\hline Soft speech sounds & 52.8 \\
\hline \multicolumn{2}{|c|}{ What do you do when you have difficulty communicating with others with masks? } \\
\hline Ask to remove his/her mask & 3.7 \\
\hline Ask to speak one more time loudly & 35.2 \\
\hline Write down the message & 9.3 \\
\hline Do nothing & 50.0 \\
\hline Others & 1.9 \\
\hline \multicolumn{2}{|c|}{$\begin{array}{l}\text { When talking to a customer wearing a mask, have you ever used a smartphone's voice recognizer app to convert the } \\
\text { sound of speech into text messages? }\end{array}$} \\
\hline Yes & 8.9 \\
\hline No & 91.1 \\
\hline \multicolumn{2}{|c|}{ What type of hearing device do you currently use? } \\
\hline Inner ear type hearing aids & 46.7 \\
\hline Behind ear type hearing aids & 42.2 \\
\hline Cochlear implant & 11.1 \\
\hline \multicolumn{2}{|c|}{ How difficult is it to wear hearing aids due to wearing masks? } \\
\hline No difficulty & 20.0 \\
\hline Mild difficulty & 28.9 \\
\hline Moderate difficulty & 28.9 \\
\hline Severe difficulty & 17.8 \\
\hline Profound difficulty & 4.4 \\
\hline
\end{tabular}


Table 3. Continued

\begin{tabular}{|c|c|}
\hline Question & $\begin{array}{l}\text { Single or multiple } \\
\text { choice responses (\%) }\end{array}$ \\
\hline \multicolumn{2}{|c|}{ How difficult is the activity after wearing the hearing aid due to the wearing of the mask? } \\
\hline No difficulty & 24.4 \\
\hline Mild difficulty & 33.3 \\
\hline Moderate difficulty & 26.7 \\
\hline Severe difficulty & 8.9 \\
\hline Profound difficulty & 4.4 \\
\hline No response & 2.2 \\
\hline \multicolumn{2}{|c|}{$\begin{array}{l}\text { If there is a problem with the hearing aid in the COVID-19 situation or if it does not work well, are you willing to visit the } \\
\text { hearing aid center or hearing professional? }\end{array}$} \\
\hline Yes & 93.3 \\
\hline No & 6.7 \\
\hline \multicolumn{2}{|c|}{ What do you prefer if you need hearing rehabilitation services in COVID-19 situation? } \\
\hline In-person visit & 78.4 \\
\hline Remote hearing service & 3.9 \\
\hline Video telephone service & 0.0 \\
\hline Telephone service & 15.7 \\
\hline Home visit service & 2.0 \\
\hline No preference & 0.0 \\
\hline \multicolumn{2}{|c|}{ What is the current method of hearing rehabilitation services compared to before COVID-19? } \\
\hline Visit center anytime (stay the same) & 52.1 \\
\hline Visit centers only for necessary & 37.5 \\
\hline Receive remote hearing service & 2.1 \\
\hline Receive home visit service & 0.0 \\
\hline Receive telephone service & 8.3 \\
\hline Receive parcel delivery service & 0.0 \\
\hline \multicolumn{2}{|c|}{$\begin{array}{l}\text { What did you feel most uncomfortable about not being able to visit the hearing aid center or hearing professionals in } \\
\text { COVID-19 situation? }\end{array}$} \\
\hline Haring evaluation & 1.9 \\
\hline Hearing aid fitting & 52.8 \\
\hline Maintenance \& repair & 43.4 \\
\hline Auditory training & 0.0 \\
\hline Counselling & 1.9 \\
\hline \multicolumn{2}{|c|}{ Have you visited hearing aid centers or hearing professionals during social distance periods? } \\
\hline Yes & 93.3 \\
\hline No & 6.7 \\
\hline \multicolumn{2}{|c|}{$\begin{array}{l}\text { If you received face-to-face services from hearing professionals during social distance periods, what services did you } \\
\text { receive? }\end{array}$} \\
\hline Hearing evaluation & 8.8 \\
\hline Hearing aid fitting & 50.0 \\
\hline Maintenance \& repair & 39.7 \\
\hline Auditory training & 0.0 \\
\hline Counselling & 1.5 \\
\hline
\end{tabular}


Table 3. Continued

\begin{tabular}{|c|c|}
\hline Question & $\begin{array}{c}\text { Single or multiple } \\
\text { choice responses (\%) }\end{array}$ \\
\hline \multicolumn{2}{|c|}{ Have you ever received services using remote systems from hearing professionals during social distance periods? } \\
\hline Yes & 4.4 \\
\hline No & 95.6 \\
\hline \multicolumn{2}{|c|}{ If you received remote hearing rehabilitation services from the professionals, what services did you receive? } \\
\hline Hearing evaluation & 0.0 \\
\hline Hearing aid fitting & 0.0 \\
\hline Maintenance \& repair & 0.0 \\
\hline Auditory training & 0.0 \\
\hline Counselling & 2.2 \\
\hline \multicolumn{2}{|c|}{ Compared to face-to-face services, what do you think about the quality of remote hearing rehabilitation services? } \\
\hline Estimated as very low quality & 35.6 \\
\hline Estimated as low quality & 42.2 \\
\hline Estimated as the same quality & 6.7 \\
\hline Estimated as high quality & 2.2 \\
\hline Estimated as very high quality & 2.2 \\
\hline No response & 11.1 \\
\hline \multicolumn{2}{|c|}{ What service would you like to receive remotely from hearing professionals in situations like COVID-19? } \\
\hline Hearing evaluation & 5.5 \\
\hline Hearing aid fitting & 47.3 \\
\hline Maintenance \& repair & 29.1 \\
\hline Auditory training & 5.5 \\
\hline Counselling & 5.5 \\
\hline No response & 7.0 \\
\hline \multicolumn{2}{|c|}{ Have you ever used a remote video conference system (e.g., zoom) in COVID-19 situations? } \\
\hline Yes & 17.8 \\
\hline No & 82.2 \\
\hline
\end{tabular}

COVID-19: coronavirus disease 2019

Table 4. Comparison of communication difficulties when wearing masks

\begin{tabular}{lccc}
\hline Difficulties & Professionals (\%) & Clients with hearing devices (\%) & Clients without hearing devices (\%) \\
\hline No difficulties & 1.7 & 2.2 & 13.3 \\
Mild difficulties & 33.3 & 22.2 & 60.0 \\
Moderate difficulties & 45.0 & 40.0 & 13.3 \\
Severe difficulties & 13.3 & 22.2 & 6.7 \\
Profound difficulties & 6.7 & 13.3 & 6.7
\end{tabular}

보고하였고, $13.3 \%$ 는 어려움이 없다고 하였다. 또한 청각기기를 착용한 고객은 마스크를 착용한 의사소통에서 고심도의 어려움 이 있다고 응답한 경우가 $36 \%$ 로 세 그룹 중 가장 높았다.

마스크 착용 시 의사소통이 어려운 원인은 청각전문가의 경우 난청 고객이 자신의 말을 이해하기 어렵기 때문이며(63.6\%), 청각 기기를 착용한 난청인의 경우 말소리가 작아졌기 때문으로(53\%)
응답하였다. 이외에도 입 모양 등 시각적 단서 활용의 어려움 (36\%)도 마스크 착용 시 대화가 어려운 것도 이유로 꼽았다. 설 문 결과 마스크 착용 시 난청인 본인과 대화 상대자 모두 의사소 통의 어려움을 겪고 있음을 보여주었다. 또한 난청 고객의 청력 이 나쁠수록 마스크 착용 시 의사소통의 어려움은 더 커지는 것 으로 나타났다(Spearman correlation, $p<0.05, \mathrm{r}=0.607$ ). 
마스크와 청각기기를 동시에 착용하였을 때 청각기기에 따른(귓 속형 보청기 21명, 귀걸이형 보청기 19명, 인공와우 5명) 어려움 을 비교한 결과 귀걸이형 보청기를 착용하였을 때 다른 청각기기 보다 착용과 활동 측면에서 더 심한 어려움을 경험한 것으로 나 타났다(Kruskal Wallis, $p<0.05$ ).

\section{DISCUSSIONS}

본 연구에서는 코로나19 상황에서 국내 청각재활서비스의 제 공 및 이용 현황을 파악하고자 청각전문가와 난청인 총 120 명을 대상으로 설문을 시행하였다. 먼저 청각전문가 설문 결과 코로나 19 이후 대면 청각서비스의 제공은 감소하였으나 원격 등 다른 대안적 방법보다는 여전히 대면서비스를 가장 많이 제공하고 선 호하고 있음을 보여 주었다. 또한 보청기 적합서비스가 코로나19 상황에서 가장 우려되는 서비스 항목으로 나타났고 그 다음으로 는 관리 및 수리, 청력검사의 순이었다. 청각전문가의 $32 \%$ 만이 원격 청각서비스 이용 경험이 있어 전문가의 원격서비스 활용도 는 낮은 것으로 나타났고 원격 서비스의 질에 대한 평가도 매우 낮았다. 또한 원격 보청기 적합의 제공 대한 요구가 가장 많음을 확인할 수 있었다. 원격 청각서비스의 단점으로는 원격 시스템의 활용 지식과 시스템 부족에 대한 응답이 $39 \%$ 로 가장 높았다.

난청 고객은 코로나19 상황에서도 여전히 대면서비스를 선호 하며 대부분의 응답자가 청각전문가를 방문하고 있음을 알 수 있었다. 또한 가장 필요한 서비스는 청각전문가와 마찬가지로 보 청기 적합이었고 다음으로 관리 및 수리 영역이었다. 응답 고객 의 $96 \%$ 는 원격 청각서비스를 받은 경험이 없으며 원격서비스의 질에 대한 평가는 매우 낮았으며, 서비스 항목 중 원격 보청기 적 합서비스에 대한 요구가 가장 많았다.

마스크의 착용은 청각전문가와 난청인 모두에게 의사소통의 어려움을 초래하였다. 그 주된 원인은 난청 고객이 상대방의 말 소리를 잘 이해하지 못하기 때문이며 이는 마스크로 인해 상대 방의 말소리가 작아지거나 고주파수가 여과되고 입 모양 등 시각 적 단서 활용의 제약과 관련이 있다. 또한 청력이 나쁠수록 의사 소통의 어려움이 더 커지는 것으로 나타났고, 청각기기와 마스 크를 동시에 착용한 경우 청각기기의 착용과 활동에서의 어려움 이 가중됨을 알 수 있었다. 특히 귀걸이형 보청기의 경우 그 어려 움은 더 커졌다.

본 설문 결과를 통해 현재까지 코로나19 상황에서 국내 청각 재활서비스에 대한 다음 몇 가지 내용을 확인할 수 있었다. 첫째, 코로나19 기간 동안 국내 대면 청각재활서비스 예약은 감소하였 으나 청각전문가와 난청 고객 모두 대면 방식의 청각재활서비스 를 여전히 선호하고 시행하고 있다. 둘째, 보청기 적합 관리는 코 로나19 상황에서도 청각전문가와 난청 고객이 중요시하는 청각
재활서비스 항목이다. 셋째, 마스크의 착용은 난청인과 청각전문 가 모두에게 의사소통의 어려움을 초래하였으며 청력이 나쁠수 록 그 어려움은 더 커졌다. 어려움의 주된 원인은 마스크로 인한 소리 감쇄와 입 모양 등을 읽지 못해 난청인이 대화 내용을 정확 히 파악하지 못하는 데 있다. 넷째, 마스크와 청각기기를 동시에 착용하는 경우 청각기기 착용과 활동에서의 어려움을 초래할 수 있으며 귀걸이형 보청기의 착용은 그 어려움을 더 가중시킨다. 다섯째, 국내 청각전문가와 난청 고객 모두 원격 청각서비스를 활용하고 있지 않으며 원격서비스의 질에 대한 평가도 매우 낮 은 것으로 나타났다. 원격 청각서비스에 대한 교육, 시스템 구축, 원격서비스 항목의 확대, 원격 시스템이 내장된 청각기기의 보급 등 원격 청각서비스를 대안적 서비스로 활용하기 위해서는 관련 지식, 인식개선 및 서비스 시스템 구축이 필요하다.

응답자의 약 $11 \%$ 만 코로나 19 상황에서 직접 대면서비스를 위 해 센터를 방문하겠다는 Gaeta(2020)의 연구와 달리, 본 설문 의 국내 응답자는 $93 \%$ 가 직접 센터를 방문한다고 답하여 차이 가 있었다. 이는 미국과 국내의 팬데믹 상황 및 정부 대응의 차 이와 연관이 있을 것이다. 우리나라의 사회적 거리두기 정책은 상대방과의 $2 \mathrm{~m}$ 거리 유지와 5 인 이상 집합 금지를 골자로 하였 지만, 미국은 사회 전반에 걸친 봉쇄 수준의 대응이었다. 또한 2020년 6월 1일 기준 미국 내 코로나19 사망자 3,547,203명, 감 염자 170,593,560명이었으며(Centers for Disease Control and Prevention, 2020), 국내보다 훨씬 심각한 수준으로 코로 나 19 가 확산되어 외출과 대인 접촉을 크게 자제하는 상황이 이 러한 차이를 가져오는데 영향을 미쳤을 것이다.

또한 Gaeta(2020)의 연구에서 53\%의 고객이 마스크 착용으 로 인한 의사소통의 어려움을 보고하였으나, 본 연구에서는 고 객의 $80 \%$, 청각전문가의 $90 \%$ 이상이 마스크의 착용으로 경도 이상의 어려움을 겪는다고 보고하였다. 본 설문에서는 응답의 척도를 5 단계로 구분하여 어려움 없음의 단계에서, 경도, 중도, 고도, 완전 어려움의 단계로 구분하여 응답하도록 하였고 이는 응답률 차이에 영향을 미쳤을 것으로 생각된다. 또한 국내 환경 적 특성상 미국의 경우보다 더 자주, 오래 마스크를 착용하고 밀 착 생활을 했을 가능성이 높기 때문에 마스크 착용의 불편함을 좀 더 많이 인지하는 데 영향을 미쳤을 것으로 생각된다.

한 가지 흥미로운 사실은 마스크의 착용으로 대화 시 어려움 이 있을 때 청각전문가는 본인의 말을 난청 고객이 잘 알아들을 수 있도록 크고 분명하게 다시 말해준다고 응답(60\%)한 경우가 가장 많았으나, 난청 고객은 아무런 요구나 조치를 취하지 않는 다고 응답한 경우(50\%)가 가장 많아 난청 고객이 대화 시 상대 방의 말을 잘 이해하지 못한 경우에도 아무런 행동도 취하지 않 는 경우가 많은 것을 확인할 수 있었다. Gaeta(2020)의 연구에 서도 본 연구 결과처럼 응답의 $78 \%$ 가 아무 행동을 취하지 않는 
다고 하여, 난청인이 의사소통이나 대화 시 다소 소극적인 태도 를 취하는 경향이 있음을 보여주었다. 마스크 착용 시 의사소통 의 단절을 막고 원활한 의사소통 촉진을 위한 의사소통 전략 훈 련은 마스크 착용 시 원활한 의사소통에 도움이 될 수 있을 것으 로 생각된다.

미국언어청각협회에서는 마스크 착용 시 의사소통 향상을 위 한 방법으로, 대화 상대방에 집중할 것, 대화 상대자의 얼굴을 직접 마주하고 시야를 가리지 않도록 할 것, 말소리를 약간 크게 할 것, 조금 천천히 말할 것, 손이나 몸짓을 사용할 것, 대화 상대 방이 대화 내용을 이해했는지 물어보고 만약 이해하지 못한 경 우 필담 등 다른 방법을 활용할 것, 가능한 조용한 곳으로 이동 할 것, 처음 보는 사람과 대화할 경우 두 사람 모두의 의사소통 을 원활하게 할 수 있는 방법이 있는지 물어볼 것 등을 제안하고 있다(American Speech-Language-Hearing Association, 2020).

원격 청각서비스와 관련하여 Saunders and Roughley(2021) 와 Gaeta(2020)의 연구와 마찬가지로 본 연구에서도 청각전문 가와 고객 모두 원격 청각서비스의 활용과 서비스의 질에 대해 매우 낮은 신뢰도를 가지고 있음을 확인할 수 있었다. 오히려 전 문가가 고객보다 원격서비스의 질이 대면서비스보다 더 떨어질 것이라고 더 많이 응답하여 청각전문가를 위한 원격서비스 교육 과 시스템 구축이 필요함을 알 수 있었다.

Swanepoel and Hall(2010)은 유소아에서 성인까지 시행 가능한 원격 청각서비스를 선별, 진단, 중재, 환자 지각(patient perception)의 4가지 범주로 설명하였다. 선별은 videootoscopy, 이음향방사검사, 자동청성뇌간반응검사, 소음하검 사를 진단은 video-otoscopy, 청력검사(기도와 골동), 소음하 검사, 청성뇌간반응검사, 술중 감시, 평형기능검사를 포함하였 다. 중재는 보청기 적합과 확인, 인공와우 매핑, 이명치료, 보청 기 상담을 주요 내용으로 하고, 환자 지각은 고객 설문을 포함하 여, 원격 방식으로 기존의 대면 청각재활서비스 대부분의 영역에 서 시행 가능함을 언급하였다. 본 연구에 참여한 청각전문가는 $32 \%$ 만이 코로나 19 상황에서 보청기 적합 위주의 원격 청각재활 서비스를 제공하였으나 Saunders and Roughley(2021) 연구 에서는 이명재활 $65.7 \%$, 청력검사 $39 \%$, 보청기 적합 $34.9 \%$, 어 지럼증재활 $29.1 \%$ 로 보고되어 팬데믹 상황에서 국내보다 좀 더 다양한 원격 청각재활서비스를 시행한 것으로 나타났다.

한편 Singh et al.(2014)에 따르면 원격 청각서비스는 대기시 간 감소와 장소에 제약을 받지 않는다는 장점이 있으며, $\mathrm{Ng}$ et al.(2017)은 스마트폰을 활용한 원격서비스가 보청기 대상자 일 상과 배경 정보를 밀접한 상호관계 속에서 파악하고 보청기 선정 에 도움될 수 있으나 원격서비스 활용을 위한 난청인의 조작 능 력 등의 필요성을 언급하였다. 반면 Singh et al.(2014)은 고객
과 직접 대면을 하지 않는 원격서비스는 고객과 깊이 있는 대화 나 관계를 이끌어 내는데 한계가 있으며, 사람들이 원격 청각서 비스의 질이 낮을 것이라는 판단 기준을 가지고 있다고 하였다. Kim et al.(2021)은 원격서비스의 활용과 관련하여 개인 정보 보호, 규제 및 법적 관련 문제에 대한 고려가 필요함을 설명하였 고 반면 서비스의 접근성 향상, 비용 절감, 이동이 어려운 대상자 의 편리성을 장점으로 언급하였다.

본 연구에 참여한 청각전문가는 원격 청각재활서비스를 제공 할 경우 장소와 시간에 구애받지 않고, 고객이 불편함을 느낄 때 전문가의 즉각적인 조치와 대응이 가능하며 대기시간이 감소하 는 장점이 있다고 응답하여 대기시간이 줄어들고 청각서비스의 접근이 용이하다는 Singh et al.(2014)의 연구와 동일한 결과를 보였다. 고객의 입장에서도 대기시간 감소와 비용 감소에 기여한 다면 원격 서비스를 선호한다고 응답하여(Eikelboom \& Atlas, 2005) 서비스 비용과 시간은 고객과 전문가 모두에게 중요한 고 려요인이고 이는 원격 청각서비스의 가장 큰 장점 중 하나이다. 그러나 스마트폰 등 원격 시스템이나 기기의 사용이 어렵거나 원 격서비스 지원 시스템이 갖추어지지 않은 고객의 경우에는 원격 서비스의 활용이 어려우며 아직까지 고가의 원격서비스 지원이 가능한 보청기의 보급이 확대되지 않은 것도 원격 청각서비스의 활용과 관련하여 고려할 사항이다.

코로나19 팬데믹 상황은 기존 대면 방식의 청각재활서비스 에 변화를 가속화하고 있다고 해도 과언이 아닐 것이다. 아직까 지 국내 청각전문가와 난청 고객 모두 이에 대응할 수 있는 전 략과 방안이 부재하며 관련 시스템 또한 미비한 실정이다. 미 국(American Academy of Audiology, 2020; American Speech-Language-Hearing Association, 2021), 호주 (Audiology Australia, 2021), 영국(British Academy of Audiology, 2021) 등에서는 코로나19와 비대면 시대의 청각재 활서비스 활성화를 위한 관련 지침을 제공하고 기술적, 제도적 시스템을 갖추기 위한 노력을 하고 있다. 미국청각언어협회는 전 문가를 위한 원격 청각서비스 온라인 교육을 이미 시행하고 있 으며 원격서비스의 비용, 내용, 방법 등에 대한 정보를 제공하고 있다. 호주와 영국도 코로나19 상황에서 청각재활서비스 제공을 위한 지침을 마련하고 비대면 시대의 원격 청각서비스 제공을 위 한 방안을 준비하고 있다. 이외에도 앞서 소개한 마스크 착용 시 의사소통 전략이라든지 마스크 착용을 고려한 청각기기의 선택 과 적합을 위한 정보를 제공하기도 한다. 국내 청각재활서비스도 코로나19 상황에서 청각재활서비스의 질 향상과 효율적인 서비 스 제공을 위한 지침과 대응 방안을 마련하고 시스템 구축 및 교 육에 대한 좀 더 많은 지원과 관심이 필요할 것이다. 
중심 단어 : 청각서비스, 코로나 19 , 팬데믹, 청각재활, 원격 청각.

\section{Ethical Statement}

This study was approved by the Institutional Review Board of Hallym University of Graduate Studies (\#HUGSAUD509467).

\section{Acknowledgments}

We would like to thank you all survey respondents of this study.

\section{Declaration of Conflicting Interests}

There is no conflict of interests.

\section{Funding}

This work was supported by the Ministry of Education of the Republic of Korea and the National Research Foundation of Korea (2019S1A5A 8038153).

\section{Author Contributions}

Conceptualization: InOn Kim, Soo Hee Oh. Data curation: InOn Kim, Soo Hee Oh. Investigation: InOn Kim, Soo Hee Oh. Validation: InOn Kim, Soo Hee Oh. Writing-original draft: InOn Kim, Soo Hee Oh. Writing—review \& editing: InOn Kim, Soo Hee Oh. Approval of final manuscript: InOn Kim, Soo Hee Oh.

\section{ORCIDiD}

InOn Kim https://orcid.org/0000-0003-4284-4765

Soo Hee Oh https://orcid.org/0000-0002-3745-1484

\section{REFERENCES}

Alqudah, S., Zaitoun, M., Alqudah, O., Alqudah, S., \& Alqudah, Z. (2021). Challenges facing users of hearing aids during the COVID-19 pandemic. International Journal of Audiology, 60(10), 747-753.

American Academy of Audiology. (2020, November 5). More Speech Degradations and Considerations in the Search for Transparent Face Coverings during the COVID-19 Pandemic, Audiology Today. American Academy of Audiology. Retrieved from https://www. audiology.org/news-and-publications/audiology-today/articles/ more-speech-degradations-and-considerations-in-the-search-fortransparent-face-coverings-during-the-covid-19-pandemic/.

American Speech-Language-Hearing Association (ASHA). (2020, October 3). Communicating Effectively While Wearing Masks and Physical Distancing. ASHA. Retrieved from https://www.asha.org/ public/communicating-effectively-while-wearing-masks-andphysical-distancing/.
American Speech-Language-Hearing Association (ASHA). (2021, January 24). Telepractice Resources during COVID-19. ASHA. Retrieved from https://www.asha.org/about/telepractice-resourcesduring-covid-19/.

Atcherson, S. R., McDowell, B. R., \& Howard, M. P. (2021). Acoustic effects of non-transparent and transparent face coverings. The Journal of the Acoustical Society of America, 149(4), 2249-2254.

Audiology Australia. (2021, September 21). COVID-19 Information for Audiology Australia Members. Audiology Australia. Retrieved from https://audiology.asn.au/ccms.r?Pageid=10056\&tenid=AUD A\&DispMode $=$ goto\%7C10212.

British Academy of Audiology. (2021, January 15). Audiology and Otology Guidance during COVID19 January 2021. British Academy of Audiology. Retrieved from https://www.baaudiology.org/app/ uploads/2021/01/Audiology-and-Otology-Guidance-duringCOVID19-January-2021.pdf.

Centers for Disease Control and Prevention. (2020). Coronavirus Disease 2019. Centers for Disease Control and Prevention. Retrieved from https://covid.cdc.gov/covid-data-tracker/\#datatracker-home.

Corey, R. M., Jones, U., \& Singer, A. C. (2020). Acoustic effects of medical, cloth, and transparent face masks on speech signals. The Journal of the Acoustical Society of America, 148(4), 2371-2375.

Demetriou, C., Ozer, B. U., \& Essau, C. (2015). Self-report questionnaires. In Cautin, R. L. \& Lilienfeld, S. O. The Encyclopedia of Clinical Psychology (pp.1-6). Hoboken, NJ: John Wiley \& Sons, Inc.

Eikelboom, R. H. \& Atlas, M. D. (2005). Attitude to telemedicine, and willingness to use it, in audiology patients. Journal of Telemedicine and Telecare, 11 Suppl 2, S22-S25.

Gaeta, L. (2020). Survey of hearing health during the COVID-19 pandemic: Implications for service delivery. American Journal of Audiology, 29(4), 944-947.

Goldin, A., Weinstein, B., \& Shiman, N. (2020). Speech blocked by surgical masks becomes a more important issue in the era of COVID-19. Hearing Review, 27(5), 8-9.

Ioannidis, J. (2021). Infection fatality rate of COVID-19 inferred from seroprevalence data. Bulletin of the World Health Organization, 99(1), 19-33F.

Kim, J., Jeon, S., Kim, D., \& Shin, Y. (2021). A review of contemporary teleaudiology: Literature review, technology, and considerations for practicing. Journal of Audiology and Otology, 25(1), 1-7.

Ministry of Health and Welfare. (2021, June 4). Coronavirus Disease-19, Republic of Korea. Ministry of Health and Welfare. Retrieved from http://ncov.mohw.go.kr/.

Ng, S. L., Phelan, S., Leonard, M., \& Galster, J. (2017). A qualitative case study of smartphone-connected hearing aids: Influences on patients, clinicians, and patient-clinician interactions. Journal of the American Academy of Audiology, 28(6), 506-521.

Nguyen, D. D., McCabe, P., Thomas, D., Purcell, A., Doble, M., Novakovic, D., et al. (2021). Acoustic voice characteristics with and without wearing a facemask. Scientific Reports, 11(1), 5651.

Saunders, G. H. \& Roughley, A. (2021). Audiology in the time of COVID-19: Practices and opinions of audiologists in the UK. International Journal of Audiology, 60(4), 255-262.

Singh, G., Pichora-Fuller, M. K., Malkowski, M., Boretzki, M., \& Launer, S. (2014). A survey of the attitudes of practitioners toward teleaudiology. International Journal of Audiology, 53(12), 850-860.

Swanepoel, D. W. \& Hall, J. W., 3rd. (2010). A systematic review of telehealth applications in audiology. Telemedicine and e-Health, 16(2), 181-200. 